\title{
Brain protein project enlists mice in 'dry run'
}

\section{Alison Abbott, Munich}

A major global project to catalogue the proteins in the human brain has been launched with a pilot that will analyse proteins expressed in the mouse brain.

Scientists from around the world agreed on the pilot phase at a meeting in Düsseldorf, Germany, on 5-6 September, and decided that the long-term aims of the project should focus on proteins that are relevant to Alzheimer's and Parkinson's diseases.

But they also discussed the technical and scientific problems facing the Human Brain Proteome Project (HBPP) as it aims for its final goal of cataloguing the protein-expression profile, or proteome, of the human brain in normal health, in disease and in old age.

Forty-five scientists from ten countries, mostly in Europe, attended this first HBPP meeting. The project is being led by protein chemists Helmut Meyer from the University of Bochum and Joachim Klose from Humboldt University in Berlin, who are co-directing the world's largest brainproteomics project to date, begun in 2000 with $€ 15$ million (US\$17 million) in funding from the German ministry of research.

The HBPP concept was launched in April under the umbrella of the Human Proteome Organisation (HUPO), the global group for public proteomics initiatives. It joins existing HUPO initiatives to determine the
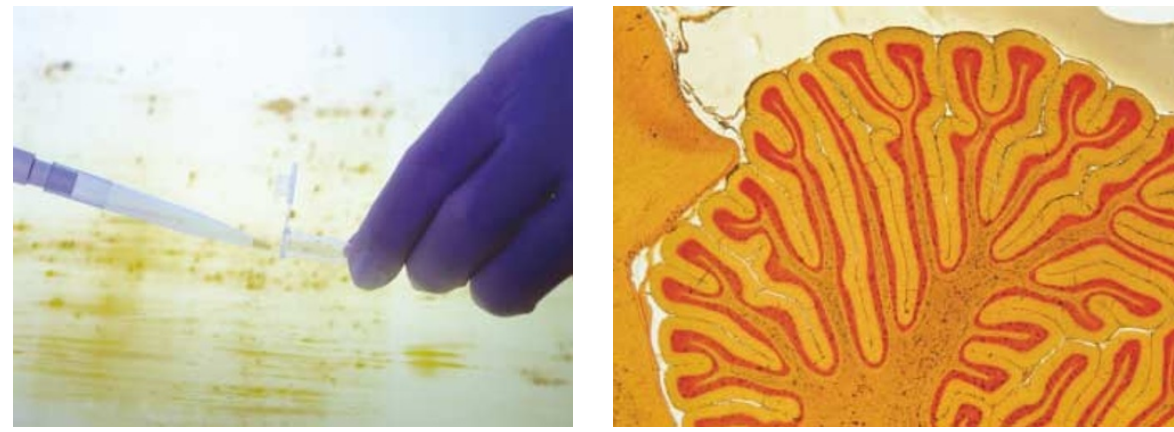

Hands-on heads: proteomics researchers hope to sample protein levels in the human brain (right).

proteomes of human plasma and liver.

All of these initiatives must cope with the difficulties of measuring thousands, or even hundreds of thousands, of proteins, some of the most biologically important of which may be present at verylowlevels and buried in lipid membranes. But the brain project also has the unique problem of requiring access to fresh, healthy human material. To begin the project, the HBPP needs 10-20 human brains.

Autopsied brains are a potential source of tissue, and have the advantage of being 'normal' if they come, for example, from otherwise healthy road-accident victims. But autopsy material is never fresh, and many proteins will already have been degraded if an autopsy is performed more than a fewhours after death.

"The problem of degradation of brain

\section{US selects regional biodefence hubs}

\section{Rex Dalton, San Diego}

The US National Institutes of Health (NIH) has awarded \$350 million in grants to eight university consortia to set up research centres that will spearhead the country's biodefence research effort.

The consortia will each receive between $\$ 35$ million and $\$ \mathbf{5 0}$ million over five years from the NIH's National Institute of Allergy and Infectious Diseases (NIAID) to boost research programmes on defences against biological weapons.

Anthony Fauci, the NIAID's director, says: "The new programme provides a coordinated and comprehensive mechanism to support the interdisciplinary research that will lead to new and improved therapies, vaccines, diagnostics and other tools to protect the citizens of our country and the world."

By the end of this month the NIAID will also announce one or two institutions that could receive as much as $\$ 120$ million to build biological containment facilities for research on the deadliest pathogens.

In the aftermath of the terrorist attacks of 11 September 2001 and the subsequent anthrax mailings, the NIAID boosted its bioweapons defence programmes by increasing grants and inviting institutions to host the new research centres.

About 15 consortia applied for the scheme. The winners, which were announced on 4 September, are led by Duke University in Durham, North Carolina; Harvard Medical School in Boston, Massachusetts; the New York State Department of Health; the University of Chicago and Northwestern University, both in Illinois; the University of Maryland in Baltimore; the University of Texas Medical Branch at Galveston; the University of Washington in Seattle; and Washington University in St Louis, Missouri.

"While this project has been driven by concerns about bioterrorism, the knowledge gained could have a significant impact on humanity's eternal battle against all infectious diseases," says geneticist Olaf Schneewind of the University of Chicago, one of the programme's principal investigators. proteins after death has dogged brain researchers for decades," says Hans Kretzschmar, a neurobiologist at the University of Munich and the coordinator of BrainNet Europe, a network of ten brain banks. "No one yet knows just how bad it is - and just how much it will affect our project."

The HBPP will investigate the rates of protein degradation after death, says Meyer. In the meantime, Kretzschmar says he and his colleagues will try to acquire post-mortem brains no later than three hours after death, the earliest that coroners can proceed with an autopsy after receiving permission from relatives, which is required in western Europe.

The one-year mouse pilot project will analyse proteins in the whole brains of a commonly used lab strain; 16-day-old embryos, 7-day-old mice and 8-week-old adult animals will be investigated. The project will catalogue the proteins and compare different methods used by the various HBPP labs - of which there are around 50 so far, mostly in Europefor their ability to reliably quantify differences in the expression of 5,000-10,000 proteins in each age group. "We'll be looking at all the proteins we can with current technologies and this includes some of the low-abundance ones, not just the easy ones," says Meyer.

Work on healthy human brains will begin as they become available. Proteomes will be analysed in four relevant brain areas rather than in the whole brain. Two of the areas - the temporal lobe and the hippocampus, which can also sometimes be acquired from surgery - are important in Alzheimer's. The other two - the substantia nigra and the basal ganglia, which cannot be obtained from surgery - are important in Parkinson's. These will eventually be compared with autopsied material from Parkinson's or Alzheimer's patients. But given the limitations on obtaining human material, much of the work will first be done in mouse models of the diseases.

Quality-controlled data from the HBPP will be made publicly available on the Internet, in accordance with HUPO's philosophy. The project's participants will seek funds from local and international sources.

www.hbpp.org 